\title{
Effects of Platelet-Derived Endothelial Cell Growth Factor and Doppler Perfusion Index in Patients with Colorectal Hepatic Metastases
}

\author{
Xueming Jiang ${ }^{\mathrm{a}}$ Zhixiang Zhang ${ }^{\mathrm{a}} \mathrm{Na} \mathrm{Zhao}^{\mathrm{b}} \quad$ Xianghui He $^{\mathrm{a}, \mathrm{b}}$ Hao Guo a, b \\ a Department of General Surgery, Tianjin Medical University General Hospital, Tianjin, China; \\ bTianjin General Surgery Institute, Tianjin Medical University General Hospital, Tianjin, China
}

\section{Keywords}

Colorectal neoplasms · Hepatic metastases · Doppler perfusion index, DPI - Platelet-derived endothelial cell growth factor, PD-ECGF

\section{Summary}

Background: We aimed to find out if there is a correlation between Doppler perfusion index (DPI) and plateletderived endothelial cell growth factor (PD-ECGF), which is an angiogenic factor with angiopoietic function, in patients with colorectal carcinoma. Methods: 50 colorectal carcinoma patients (22 cases with liver metastases, 28 cases without liver metastases) and 50 healthy controls were assessed with Doppler ultrasound as a preoperative evaluation. PD-ECGF expression in postoperative specimens of the 50 cases with colorectal carcinoma was assayed by immunohistochemistry and real-time polymerase chain reaction methods. Results: The mean DPI value was $0.29 \pm 0.05$ in patients suffering from colon cancer with hepatic metastases and $0.12 \pm 0.03$ in the healthy control group. The DPI value was significantly higher in patients with liver metastases ( $p<0.05)$. PDECGF expression in patients with colorectal liver metastases was significantly higher than that in the group without liver metastases $(p<0.05)$. A positive correlation was found between DPI value and PD-ECGF expression in patients with liver metastases $(p<0.05)$. Conclusions: DPI and PD-ECGF may be valuable factors when screening hepatic metastases in patients with colorectal cancer and serve as practical measurements in postoperative follow-up.

(c) 2016 S. Karger GmbH, Freiburg

\section{Introduction}

Liver metastasis is a common consequence of colorectal carcinoma. The detection of hepatic metastases is necessary for an exact staging and planning of the treatment [1]. It is known that conventional imaging techniques are of limited value in identifying small liver metastases. There is evidence that the presence of even microscopic liver metastases is associated with subtle changes in liver blood flow [2]. Doppler ultrasonography (US) has the ability to measure liver blood flow directly [3, 4]. In order to assess the altered hepatic hemodynamics due to tumoral angiogenesis of liver metastasis, Doppler perfusion index (DPI), which is the ratio of the hepatic artery flow to the total liver blood (hepatic artery + portal vein) flow measured by Doppler US, was introduced by means of dynamic scintigraphy and was found to have a high accuracy. Thus, it was postulated that even early small hepatic metastases may induce alterations of hepatic blood flow [3-5]. DPI, as an inexpensive and non-invasive method, does not require usage of contrast material or ionizing radiation to investigate hemodynamic alterations of the liver [5].

Recently, there was an increase in imaging approaches combined with biological measurements to investigate the relationship between vascularization and metabolism. Platelet-derived endothelial cell growth factor (PD-ECGF) is known as thymidine phosphorylase (TP). Numerous immunohistochemical and PD-ECGF activity studies have shown an increased PD-ECGF expression and activity in a wide range of tumors compared with normal, healthy tissues [6-8]. High PD-ECGF expression in these tumor sites has clearly been related to a high microvessel density, the induction of metastasis, and a poor prognosis for the patient [9-11]. The location of PD-ECGF expression varies between tumor type and grade and has been reported to be highly expressed in many tumor cells [12], in the invasive part of the tumor [11], or in the tumor stromal cells $[13,14]$. PD-ECGF is involved in two different yet overlap-

\section{KARGER}

Fax +497614520714
Dr. Hao Guo

No. 154 Anshan Road, Heping District, Tianjin, 300052, People’s Republic of China guohaoay@163.com 
Fig. 1. a Normal hepatic arterial blood flow; $\mathbf{b}$ increase of hepatic arterial blood flow in patients with liver metastases; c normal portal vein blood flow; d decrease of portal vein blood flow in patients with liver metastases; e DPI value in the liver metastases group was significantly higher than in the group without metastases and the control group. Data are means \pm standard error of the mean and are representative of at least three independent experiments. NS $=$ Not significant; ${ }^{* *} \mathrm{p}<0.01$ compared to controls.
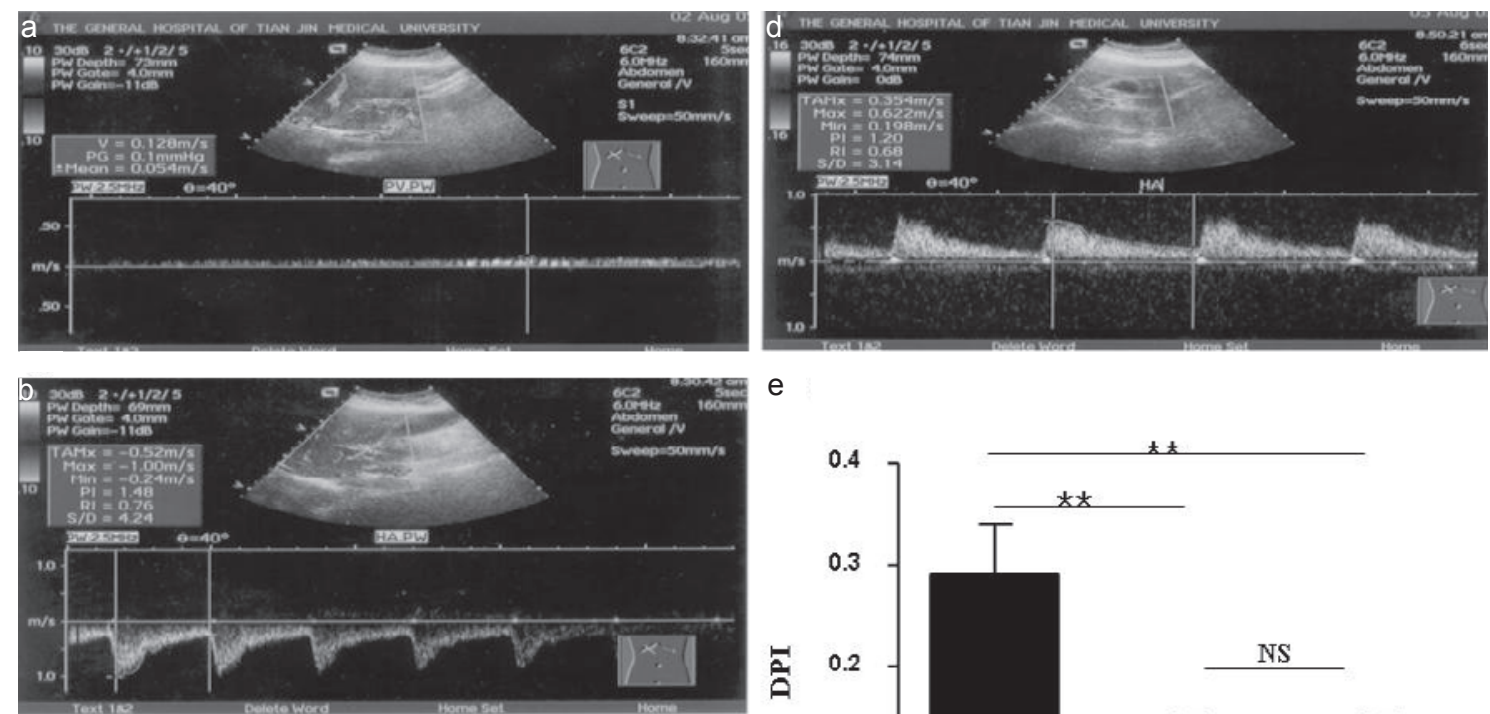

e

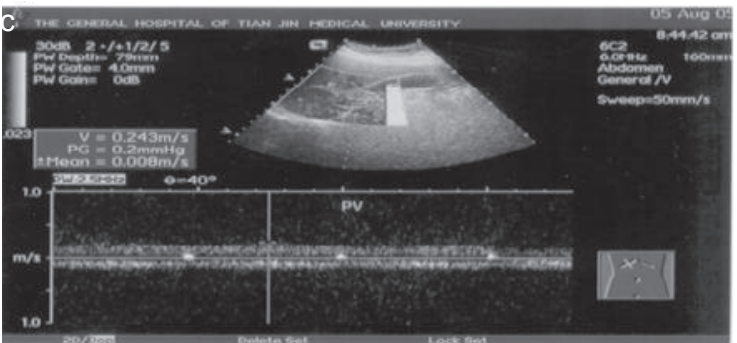

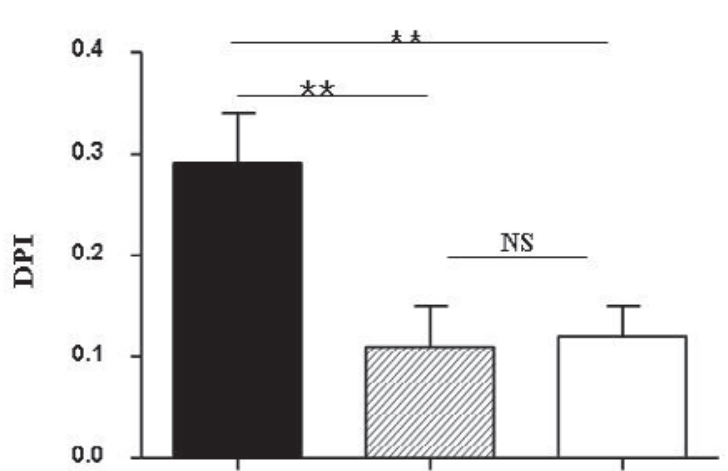
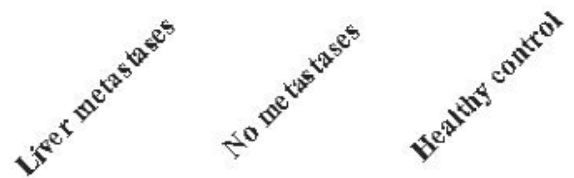

ping actions. Firstly, it is associated with a higher invasive property and metastatic potential of the cancer cells $[7,15]$. Secondly, it is related to an increased angiogenesis [16].

The aim of this study is to investigate changes of hepatic perfusion and PD-ECGF expression in patients with liver metastases of colorectal cancer by means of DPI measurements and PD-ECGF mRNA and protein expression, to figure out any correlation between liver hemodynamics and tumor molecular biology, and to explore novel complementary diagnostic or predictive parameters in the clinical management.

\section{Patients and Methods}

\section{Patients}

This study was approved by the local ethics committee, and informed written consent was obtained from all of the patients. 50 patients awaiting surgery for colorectal cancer (age range 32-81 years) and 50 healthy individuals without signs of malignant disease (age range 30-80 years) were enlisted. 22 patients with synchronous hepatic metastases and 28 patients without metastases from colorectal cancer were included in this prospective study. Metastases were diagnosed by sonography and confirmed by computed tomography or nuclear magnetic resonance imaging before surgery.

\section{DPI Measurement}

Liver perfusion was assessed by a color duplex Doppler scanner (SEQUOIA 512 U.S.; Siemens, Munich, Germany) with built-in algorithms for calculating time-averaged mean blood velocity and blood flow. A convex 3.5-MHz phased linear array probe was used for all measurements. All measurements were performed with subjects in the supine position and during expiration after $12 \mathrm{~h}$ of fasting. Spectral analysis was determined based on the technique described in previous studies [3,17-19]. The parameters of portal vein and hepatic artery measured by the SEQUOIA 512 Doppler were the following: diameter, time-averaged mean velocity, and blood flow. Volume flows of the proper hepatic artery (PHAF) and portal vein (PVF) were calculated by means of the time-averaged blood velocity and the diameter for each vessel. The hepatic artery was measured as near as its origin, given the angle of insonation or acoustic interference from adjacent vessels at the porta hepatis. The portal vein was interrogated at the site of the crossing of the right hepatic artery, and measurements of diameter and time-averaged velocity were obtained. All measurements were performed with insonation angles between longitudinal axis and sound wave being less than $60^{\circ}$. The measurements were recorded electronically. DPI value was calculated by the following formula: DPI = PHAF / $(\mathrm{PHAF}+\mathrm{PVF})$. The intraobserver and interobserver reproducibility of DPI measurements are only clinically acceptable when repeated measurements are performed by experienced examiners.

\section{PD-ECGF mRNA Expression}

Frozen colorectal specimens obtained from the above 50 patients with primary colorectal cancer which underwent surgery at our institute were collected to investigate PD-ECGF mRNA expression. Total RNA was extracted from the colorectal samples using Trizol reagent according to the manufacturer's protocol (Invitrogen, Carlsbad, CA, USA). Every 500 ng RNA extracted was reverse transcribed to cDNA according to the manufacturer's protocol (TaKaRa Bio Inc., Dalian, China). PD-ECGF mRNA expression was determined by real-time fluorescence quantitative polymerase chain reaction (PCR) (Opticon II; Bio-Rad Laboratories Inc., Hercules, CA, USA), using the SYBR Green qPCR Kit according to the manufacturer's instruction (Invitrogen, Carlsbad, CA, USA). The cycle parameters were: $50{ }^{\circ} \mathrm{C}$ for $10 \mathrm{~s}$ and $95^{\circ} \mathrm{C}$ for $10 \mathrm{~min}$, followed by $42 \mathrm{cy}$ cles at $95^{\circ} \mathrm{C}$ for $15 \mathrm{~s}$ and $60^{\circ} \mathrm{C}$ for $1 \mathrm{~min}$. At the end, a melting curve analysis was performed to confirm the specificity of the amplification. The level of expression for each mRNA is the ratio against the amounts of glyceraldehyde 3-phosphate dehydrogenase (GAPDH) used as an internal control. PD-ECGF 
primer: forwards 5'-AGAGCCCAGAGCAGATGCAGG-3', and reverse 5'-CACGGTGGCTGTCACATCTCT-3'. GAPDH primer: forwards 5'-GAAGGTGAAGGTCGGAGTC-3', and reverse 5'-GAAGATGGTGATGGGATTTC-3' (Invitrogen, Shanghai, China).

\section{Determination of PD-ECGF Expression by Immunohistochemistry}

Resected specimens from the 50 patients as well as normal, healthy colorec tal tissues distal to the lesions were fixed in $10 \%$ formaldehyde solution and embedded in paraffin. Sections ( $4 \mu \mathrm{m}$ thick) were cut and mounted on glass slides. Sections were dewaxed in xylene, taken through ethanol, and then incubated with $0.3 \%$ hydrogen peroxide in methanol for 30 min to block endogenous peroxidase activity. Specimens were then incubated with a 1:200 dilution of anti-dThdPase mouse monoclonal antibody (Lab Vision \& Neomarkers, Fremont, CA, USA) at $37^{\circ} \mathrm{C}$ for $1 \mathrm{~h}$. Sections were hereupon incubated with biotinylated rabbit anti-mouse immunoglobulin $\mathrm{G}$ at a dilution of 1:100 for $30 \mathrm{~min}$ followed by three washes. Slides were treated with streptavidin peroxidase reagent for $30 \mathrm{~min}$ at a dilution of 1:100 and washed with phosphate-buffered saline three times. The degree of monoclonal antibody reactivity with individual tissue sections was considered positive if unequivocal staining of cytoplasm or nuclear compartment was seen in tumor cells, regardless of the number of cells stained. The statistical results were calculated in accordance with stained areas described in a previous study [10].

\section{Statistical Analysis}

The parametric data were analyzed by the Instat version 3.06 software for Windows (GraphPad, XX). A p value less than 0.05 was defined as significant.

\section{Results}

\section{DPI Analysis}

The mean DPI values were $0.29 \pm 0.05$ for patients with liver metastases, $0.11 \pm 0.04$ for patients without metastases, and $0.12 \pm$ 0.03 in the healthy control group (fig. 1).

\section{Alteration of PD-ECGF mRNA Expression and Correlation of PD-ECGF and DPI in Patients with Hepatic Metastases of Colo- rectal Cancer}

Comparison of the level of PD-ECGF mRNA expression between the non-metastatic group $(\mathrm{n}=28)$ and the synchronous liver metastatic group $(n=22)$ was performed. Results showed that PDECGF mRNA expression was significantly increased in the synchronous liver metastatic group when compared to the non-metastatic group $(\mathrm{p}<0.0001)$. The PD-ECGF mRNA expression in colorectal carcinoma tissues is apparently higher than that of surrounding normal tissues $(\mathrm{p}<0.05)$. There was a positive correlation between PD-ECGF mRNA expression and DPI value in patients with liver metastases $(\mathrm{r}=0.52 ; \mathrm{p}=0.0127)$ (fig. 2 ).

\section{Expression of PD-ECGF in Colorectal Cancer Patients}

Our results showed that PD-ECGF is mainly expressed by interstitial cells in colorectal carcinoma tissues. The expression of PDECGF in colorectal tumor tissues is apparently higher than that of surrounding normal tissues $(\mathrm{p}<0.0001)$. Moreover, PD-ECGF expression was significantly increased in the synchronous liver metastatic group as compared to the non-metastatic group ( $\mathrm{p}<0.0001)$. There was a marked and positive correlation between PD-ECGF expression and DPI value in patients with liver metastases $(r=0.72$; $\mathrm{p}<0.0001$ ) (fig. 3).
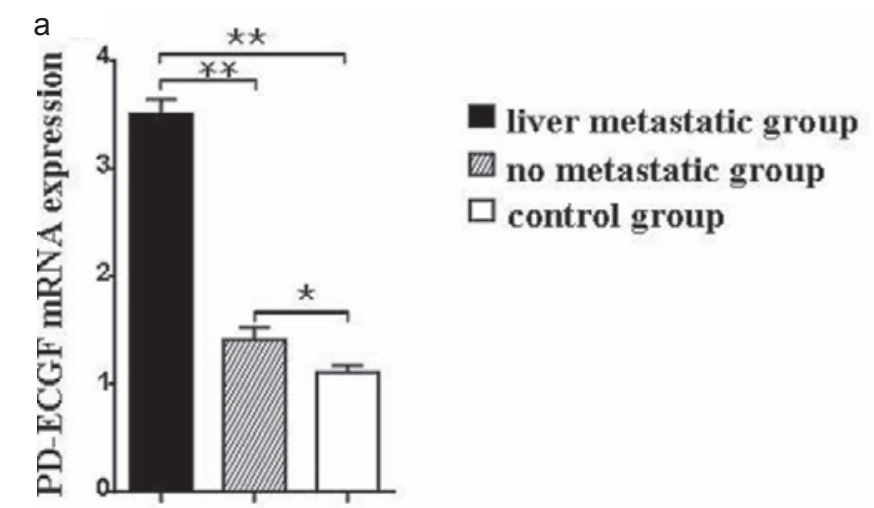

b

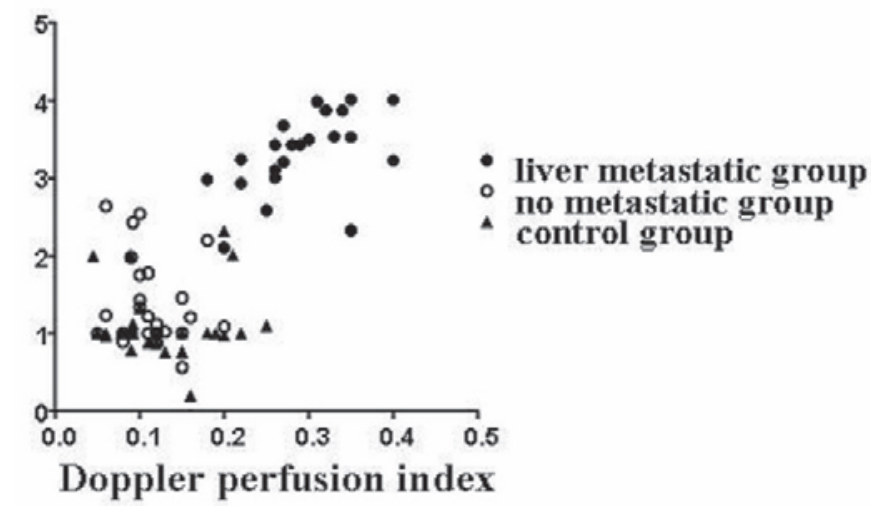

Fig. 2. a PD-ECGF mRNA expression was significantly increased in the synchronous liver metastatic group as compared to the non-metastatic group $(\mathrm{p}<$ $0.0001)$. The PD-ECGF mRNA expression in colorectal carcinoma tissues is apparently higher than that of surrounding normal tissues $(\mathrm{p}=0.0146)$. b There was a positive correlation between PD-ECGF mRNA expression and DPI value in the liver metastases group $(\mathrm{p}<0.05)$.

\section{Discussion}

DPI has been found to be increased in liver metastases of colorectal carcinoma and could be used as an indicator of metastases which are sonographically small or undetectable $[3,5,20]$. Beyond their diagnostic capability, abnormal DPI values were also reported to predict clinical outcome, lymph nodes, and liver metastases [2124]. In our study, we found the DPI values to be comparable with previous results $[3,5,25]$. The results have shown that the DPI value was $0.29 \pm 0.05$ in patients with liver metastases, $0.11 \pm 0.04$ in the non-metastatic group, and $0.12 \pm 0.03$ in the healthy control group. Obviously, DPI value was significantly higher in the liver metastases group $(\mathrm{p}<0.01)$. The DPI value was mainly studied in colorectal cancer metastases in the previous studies. The mechanisms responsible for changes in hepatic perfusion in patients with liver metastases of colorectal carcinoma are not yet fully explained. It was concluded that an increase in hepatic artery blood flow and a decrease in portal vein blood flow results in an increased DPI value $[3,5,17,26]$. Accordingly, the DPI of the liver with metastases was found to be $>0.3-0.5$, while it was $<0.15$ in benign diseases $[3,22$, 26]. Due to the small sample size of our study, it was not possible to determine a distinct cut-off value. However, we speculated that a 
Fig. 3. Expression of PD-ECGF in cancer tissue. a Immunohistochemical staining for PD-ECGF in colorectal cancer tissues (original magnification $\times 100)$. PD-ECGF is mainly expressed by interstitial cells in the colorectal carcinoma tissues; b PDECGF is rarely expressed in surrounding normal tissues (original magnification $\times 40$ ); $\mathbf{c}$ PD-ECGF expression was significantly increased in the synchronous liver metastatic group as compared to the non-metastatic group $(\mathrm{p}<0.0001)$; $\mathbf{d}$ marked and positive correlation between PD-ECGF expression and DPI value in patients with hepatic metastases $(\mathrm{p}<0.0001)$.
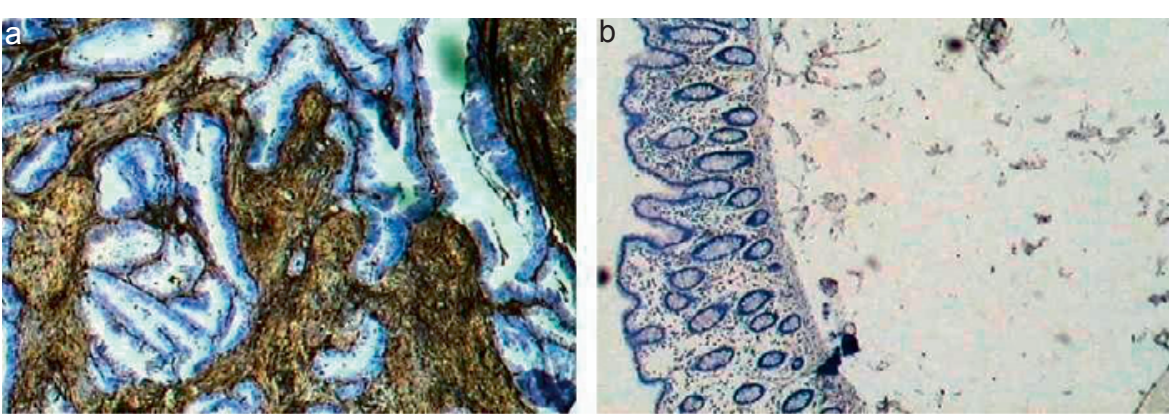

C

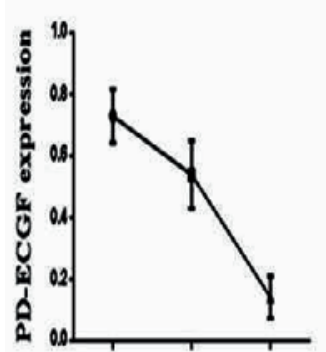

d

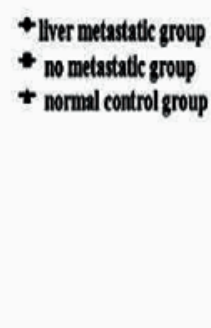

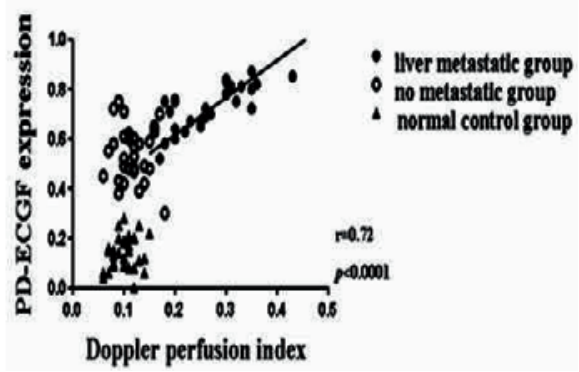

DPI $>0.29$ could be assessed as a strong possibility of metastasis, while a DPI value between 0.12 and 0.29 indicates the probable possibility of metastasis, and a DPI $<0.12$ indicates the strong possibility of absence of metastasis.

PD-ECGF has a structure similar to that of TP; therefore, these two constituents are considered to be the same substance. Previous studies have shown that PD-ECGF promoted angiogenesis and had important functions in the growth, invasion, and metastasis of colorectal carcinoma [8]. Inokuchi et al. [27] reported that patients with high PD-ECGF expression in colorectal carcinoma tissue had more new vessels in the cancer tissues and exhibited liver metastasis; thus, a bad prognosis could more easily occur in these patients. In the current study, we investigated the alteration of PD-ECGF mRNA and protein expression in colorectal cancer patients by using real-time PCR and immunohistochemical staining methods. The results showed that colorectal tumors expressed PD-ECGF. The expression of PD-ECGF in colorectal carcinoma tissues is apparently higher than that of surrounding normal tissues, especially in patients with liver metastasis. As in the previous immunohistochemical staining results described [28], we found that PD-ECGF was mainly expressed by interstitial cells surrounding the tumor tissue or infiltrating the border of the tumor. Our results showed that PD-ECGF was more expressed in tumor stroma cells than in tumor cells. We concluded that it was possible that the differentiation of tumor stroma cells could generate a mass of cytokines, such as PD-ECGF, to induce angiogenesis. By means of real-time PCR and immunohistochemical analysis, we compared the PD-ECGF expression between the primary colorectal cancer and the metastatic lesions in the liver. The expression of PD-ECGF was higher in primary tumors with metastasis than in those without metastasis. We also observed a significant difference in the expression of PD-ECGF between patients with and without metastasis. There- fore, an evaluation of the expression of PD-ECGF in advanced metastatic cancer may be useful for selecting optimized therapies for patients with colorectal cancer. Currently, no therapeutic drug targeting PD-ECGF is available for cancer patients; however, PDECGF-targeting drugs might be useful in the case of colorectal cancer with metastasis.

Colorectal tumors have to provide their own blood supply to promote growth. This process is called angiogenesis or neovascularization and is supported by numerous polypeptide growth factors and factors promoting tumor angiogenesis (such as vascular endothelial growth factor and PD-ECGF) [29]. In this study, the DPI value was found to be correlated with the expression of PDECGF, as we expected. Within the liver the new blood vessels are mostly derived from the arterial system [23]. It is known that PDECGF expression in colorectal carcinoma tissue promotes angiogenesis and liver metastasis. It is reasonable to hypothesize that PD-ECGF expression of tumors coincides with changes in tumor hemodynamics. The balance between neovascularization and metabolism of vascular growth factors could play an important role in the biological behavior of the metastases. Rapid proliferation of large tumors outgrows their vascular supply, resulting in the generation of angiogenic growth factors including PD-ECGF. Finally, the increased arterialization of the metastases leads to an increased DPI. Thus, this phenomenon could explain the positive correlation between DPI and PD-ECGF expression. Therefore, DPI and PDECGF may be valuable factors when screening hepatic metastases in patients with colorectal cancer and serve as practical parameters in the postoperative follow-up.

\section{Disclosure Statement}

The authors declare no conflict of interest. 


\section{References}

1 Alicioglu B, Sarikaya A, Bulakbasi N: Interrelationship between liver hemodynamics and tumor metabolism in liver metastases: diagnostic value of Doppler perfusion index revisited. Prague Med Rep 2013;114:103-112.

2 Hemingway DM, Cooke TG, Grime SJ, Nott DM, Jenkins SA: Changes in hepatic haemodynamics and the hepatic perfusion index during the growth and development of hypovascular HSN sarcoma in rats. Br J Surg 1991; 78:326-330

3 Leen E, Goldberg JA, Robertson J, Sutherland GR, McArdle CS: The use of duplex sonography in the detection of colorectal hepatic metastases. Br J Cancer 1991;63:323-325

4 Leen E, Angerson WJ, Wotherspoon H, Moule B, Cooke TG, McArdle CS: Comparison of the Doppler perfusion index and intraoperative ultrasonography in diagnosing colorectal liver metastases. Evaluation with postoperative follow-up results. Ann Surg 1994;220: 663-667.

5 Fong Y: Doppler perfusion index in colorectal cancer. Lancet 2000;355:5-6.

6 Ackland SP, Peters GJ: Thymidine phosphorylase: its role in sensitivity and resistance to anticancer drugs. Drug Resist Update 1999;2:205-214.

7 De Bruin M, van Capel T, Van der Born K, Kruyt FA, Fukushima M, Hoekman K, Pinedo HM, Peters GJ: Role of platelet-derived endothelial cell growth factor/ thymidine phosphorylase in fluoropyrimidine sensitivity. Br J Cancer 2003;88:957-964.

8 Bronckaers A, Gago F, Balzarini J, Liekens S: The dual role of thymidine phosphorylase in cancer development and chemotherapy. Med Res Rev 2009;29:903953.

9 Kidd EA, Yu J, Li X, Shannon WD, Watson MA, McLeod HL: Variance in the expression of 5-fluorouracil pathway genes in colorectal cancer. Clin Cancer Res 2005;11:2612-2619.

10 Nakayama Y, Inoue Y, Nagashima N, Katsuki T, Matsumoto K, Kadowaki K, Shibao K, Tsurudome Y, Hirata K, Sako T, Nagata N, Itoh H: Expression levels of thymidine phosphorylase (TP) and dihydropyrimidine dehydrogenase (DPD) in patients with gastrointestinal cancer. Anticancer Res 2005;25:3755-3761.

11 Hayashi T, Kawahara H, Kobayashi S, Kashiwagi H, Hirai K, Yanaga K: Importance of thymidine phosphorylase, dihydropyrimidine dehydrogenase and thymidylate synthase expression at the invasive front of T3 rectal cancer as prognostic factors. Hepatogastroenterology 2008;55:403-406.
12 O’Brien TS, Fox SB, Dickinson AJ, Turley H, Westwood M, Moghaddam A, Gatter KC, Bicknell R, Harris AL: Expression of the angiogenic factor thymidine phosphorylase/platelet-derived endothelial cell growth factor in primary bladder cancers. Cancer Res 1996;56: 4799-4804.

13 Liakakos T, Troupis T, Ghiconti I, Triantafyllidis S, Macheras A, Karatzas G, Pavlakis K: Immunohistochemical localization of thymidine phosphorylase in gastric cancer: is there a role of the differential expression in tumor cells and associated stromal cells? Anticancer Res 2006;26:3899-3903.

14 Ruckhaberle E, Karn T, Engels K, Turley H, Hanker L, Müller V, Schmidt M, Ahr A, Gaetje R, Holtrich U, Kaufmann M, Rody A: Prognostic impact of thymidine phosphorylase expression in breast cancer - comparison of microarray and immunohistochemical data. Eur J Cancer 2010;46:549-557.

15 Yu EJ, Lee Y, Rha SY, Kim TS, Chung HC, Oh BK, Yang WI, Noh SH, Jeung HC: Angiogenic factor thymidine phosphorylase increases cancer cell invasion activity in patients with gastric adenocarcinoma. Mol Cancer Res 2008;6:1554-1566.

16 Bijnsdorp IV, Capriotti F, Kruyt FAE, Losekoot N, Fukushima M, Griffioen AW, Thijssen VL, Peters GJ: Thymidine phosphorylase in cancer cells stimulates human endothelial cell migration and invasion by the secretion of angiogenic factors. Br J Cancer 2011;104: 1185-1192.

17 Oktar SO, Yücel C, Demirogullari T, Uner A, Benekli M, Erbas G, Ozdemir H: Doppler sonographic evaluation of hemodynamic changes in colorectal liver metastases relative to liver size. Ultrasound Med 2006;25: 575-582.

18 Călin M, Adrian D, Monica H, Halbac M, Valeanu A, Drambarean L: The role of color histograms in predicting the prognosis of patients with digestive tract adenocarcinoma. Med Ultrason 2011;13:207-214.

19 Ramnarine KV, Leen E, Oppo K, Angerson WJ, McArdle CS: Contrast-enhanced Doppler perfusion index clinical and experimental evaluation. J Ultrasound Med 2002;21:1121-1129.

20 Kopljar M, Brkljacic B, Doko M, Horzic M: Nature of Doppler perfusion index changes in patients with colorectal cancer liver metastases. J Ultrasound Med 2004; 23:1295-1300.
1 Warren HW, Gallagher H, Hemingway DM, Angerson WJ, Bessent RG, Wotherspoon H, McArdle CS, Cooke TG: Prospective assessment of the hepatic perfusion index in patients with colorectal cancer. Br J Surg 1998; 85:1708-1712.

22 Oppo K, Leen E, Angerson WJ, McArdle CS: The effect of resecting the primary tumour on the Doppler perfusion index in patients with colorectal cancer. Clin Radiol 2000;55:791-793.

23 Fuentes MA, Keith CJ, Griffths M, Durbridge G, Miles KA: Hepatic haemodynamics: interrelationships between contrast enhancement and perfusion on $\mathrm{CT}$ and Doppler perfusion indices. Br J Radiol 2002;75:17-23.

24 Miles KA, Williams RE, Yu D, Griffiths MR: Demonstrating intertumoral differences in vascular-metabolic phenotype with dynamic contrast-enhanced CT-PET. Int J Mol Imaging 2011;65:281-287.

25 Guadagni S, Pizzutilli A, Mancini E, Varrone A, Palumbo G, Amicucci G, Perri S, Deraco M, Fiorentini G: Significance of duplex/color Doppler sonography in hepatic arterial chemotherapy for patients with liver metastases from colorectal carcinoma. Eur J Surg Oncol 2000;26:381-386.

26 Kyriakopoulou K, Antoniou A, Fezoulidis IV, Kelekis NL, Dalekos GN, Vlychou M: The role of Doppler perfusion index as screening test in the characterisation of focal liver lesions. Dig Liver Dis 2008;40:755-760.

27 Inokuchi M, Uetake H, Shirota Y, Yamada H, Tajima M, Sugihara K: Gene expression of 5-fuorouracil metabolic enzymes in primary colorectal cancer and corresponding liver metastasis. Cancer Chemother Pharmacol 2004;53:391-396.

28 Yasuno M, Mori T, Koike M, Takahashi K, Toi M, Takizawa T, Shimizu S, Yamaguchi T, Matsumoto H: Importance of thymidine phosphorylase expression in tumor stroma as a prognostic factor in patients with advanced colorectal carcinoma. Oncol Rep 2005; 13: 405-412.

29 Kapoor V, McCook BM, Torok FS: An introduction to PET-CT imaging. Radiographics 2004;24:523-543. 